\title{
Numerical simulation of the effect of the coating material of contacting surfaces on thermal conductivity
}

\author{
A. D. Ezhov*, I. S. Sladkov, L. V. Bykov, and N.S. Golikov \\ Moscow Aviation Institute (National Research University), Moscow, Russia
}

\begin{abstract}
In modern space devices, a significant number of parts and assemblies of various shapes are in contact interaction. Moreover, the materials from which they are made often differ in thermophysical and mechanical properties. When designing such connections, it becomes necessary to be able to reliably carry out thermal and strength calculations, both for the entire structure as a whole, and for individual contact nodes, with the possibility of adjusting their characteristics. As a tool for regulating the conductivity of contacts, the use of coatings of contacting surfaces can be used. Modeling a metal-coating-metal contact pair allows you to optimally select the coating material and its required thickness.
\end{abstract}

\section{Introduction}

In the practice of designing complex science-intensive products, one of the immutable requirements for the design is to ensure the thermal mode of operation, both of the entire structure and its individual components and assemblies. Ensuring the specified thermal conductivity of contact joints is extremely important for spacecraft operating in the cyclic thermal loading mode. It is known that the use of surface coatings in contact allows you to adjust the value of the contact thermal conductivity, towards its decrease or increase [1,2].

Strict conditions set for the development of space vehicles, such as deadlines, limited resources, limited labor costs associated with the need to carry out a large number of experiments, make developers increasingly look for solutions by creating mathematical models of heat transfer processes. The development of a method for determining the thermal and stress-strain state of the contacting surfaces of machine parts, taking into account the real profile of surfaces, makes it possible to identify problem areas in products already at the first stages of design, and thus correct them, which allows to reduce the duration of testing and working out of the product [3-5 ].

\section{Method}

The technique developed at the Moscow Aviation Institute [5, 6] made it possible to determine the value of the thermal contact resistance (TCR) for contacts of the "solid-solid"

\footnotetext{
*Corresponding author: ezzhov@gmail.com
} 
class and did not provide for the possibility of taking into account the presence of coatings on the surface in the contact pair. The modernization of the existing technique makes it possible to add the account of the influence of the coatings of the contacting surfaces into the previously developed algorithm for determining the temperature fields in the intercontact zone.

The algorithm for determining the TCR consists in the sequential execution of the following stages. At the beginning, the profilogram of the considered samples of the contact pair is taken. The obtained data are imported for primary processing into Microsoft Excel for numerical display of the surface microgeometry and determination of the coordinates of microprotrusions and microdepressions. Based on the resulting array of points $(\mathrm{x}, \mathrm{y}, \mathrm{z}), \mathrm{a}$ microrelief surface model is built (Figure 1), and then a contact pair model is created. At the next stage, the resulting model is transferred for analysis to the ANSYS Mechanical environment, where temperature fields are calculated, taking into account the effect of mechanical and thermal loads. Based on the obtained temperature values on the surfaces of the contacting samples and on the given value of the heat flux, the TCR is determined.

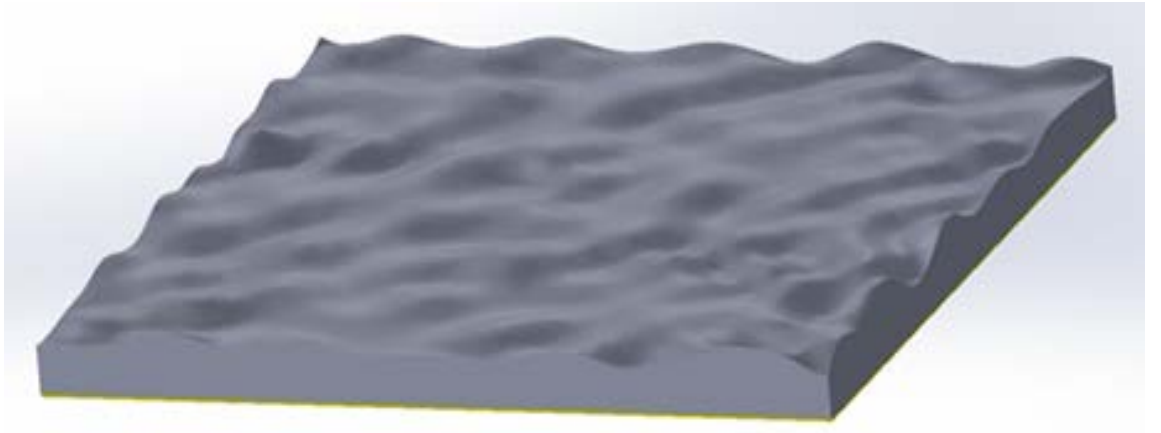

Fig. 1. Model of the surface of the microrelief.

The application of coatings on the contacting surfaces, in addition to changing the thermal conductivity of the contact due to the change in the thermal conductivity of the contacting materials and the change in the area of actual contact between the material of the part and the coating, also implies filling the microroughness of the original part with the coating material, which should lead to a decrease in the roughness of the contact surface. Observations of the relief of surfaces with coatings obtained by the galvanic method show that the characteristics of surfaces remain the same during tinning, cadmium plating, copper plating, and for applying coatings by the method of lead, the initial shape often changes towards an increase in the height of irregularities, which leads to the need to introduce additional technological operations for surface treatment [7].

The practice of using metal coatings to reduce the thermal resistance of a contact shows that it is most expedient to apply metal with a thickness equal to $2-3$ of the maximum height of microroughness of the surface profile $R_{\max }$ [8]. Figure 2 shows a model of a coated sample.

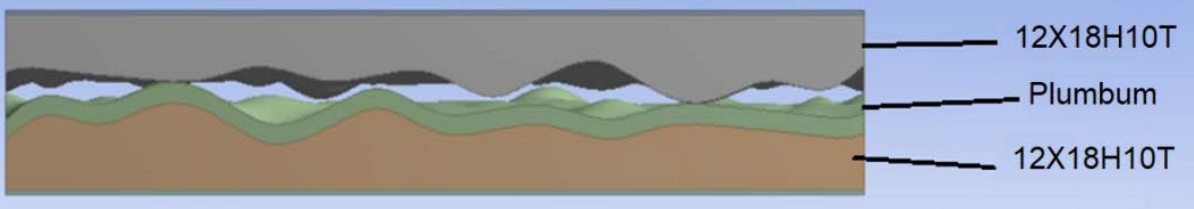

Fig. 2. Model with spray applied. 


\section{Results and Discussion}

Figure 3 shows the values of the equivalent stresses without and with the use of a lead coating at a compressive load $\mathrm{P}_{\mathrm{k}}=1 \mathrm{MPa}$. The brightest areas show the actual contact points, from which the actual contact area can be estimated.

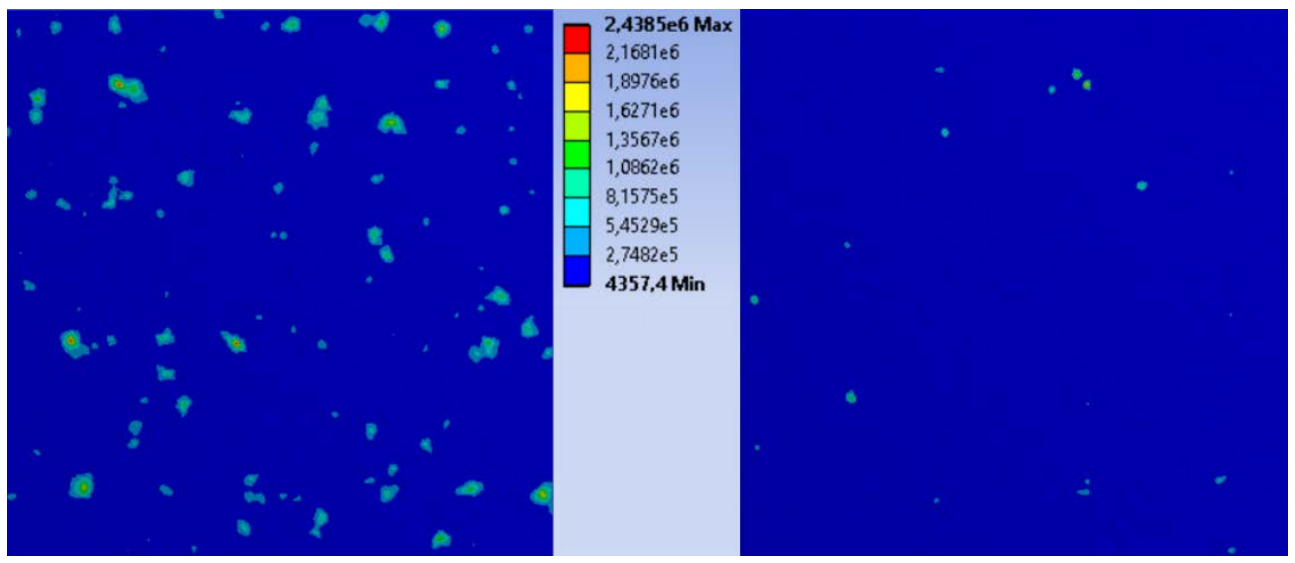

Fig. 3. Comparative analysis of equivalent stresses $(\mathrm{Pa})$ without coating and using lead coating

Thermal analysis is carried out on the basis of the deformed model obtained as a result of mechanical analysis of the contacting surfaces. Figure 4 shows that the minimum temperature differences are in the zones of direct contact, which corresponds to the physical picture, since heat flux lines thicken in the area of actual contact [9].

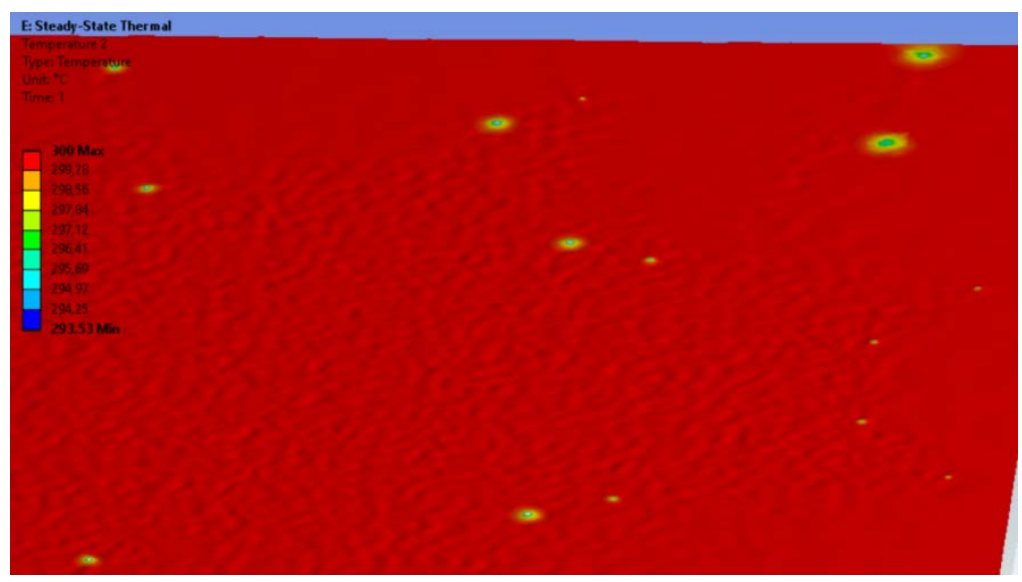

Fig. 4. Temperature field $\left({ }^{\circ} \mathrm{C}\right)$ of the contact surface at $\mathrm{P}_{\mathrm{k}}=10^{6} \mathrm{~Pa}, \mathrm{~T}=573 \mathrm{~K}, \mathrm{q}=10 \mathrm{~kW} / \mathrm{m}^{2}$

The results of calculating the TCR for a contact pair $12 \mathrm{X} 18 \mathrm{H} 10 \mathrm{~T}-12 \mathrm{X} 18 \mathrm{H} 10 \mathrm{~T}$ with a surface roughness of both samples $\mathrm{R}_{\mathrm{a}}=0.82 \mu \mathrm{m}$, as well as taking into account the coating by spraying lead on one of the surfaces, for the pressure range from $0.1 \mathrm{MPa}$ to $1 \mathrm{MPa}$ is shown in Figure 5. 


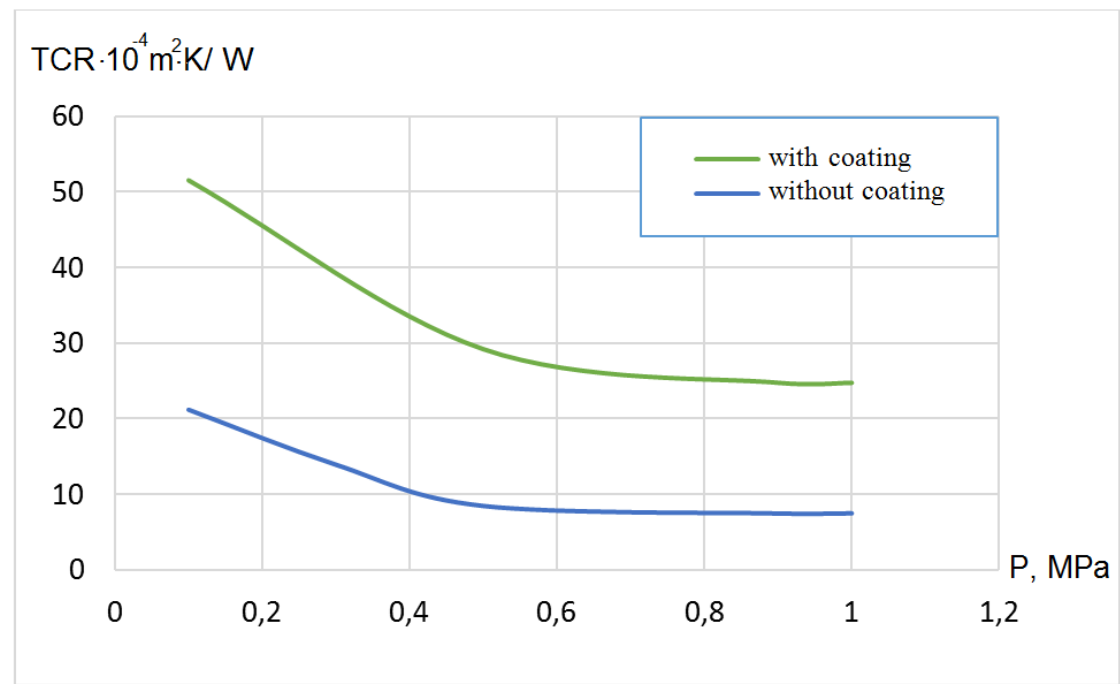

Fig. 5. Graph of the dependence of the TCR on the compressive force with and without the use of a coating of lead.

An analysis of the graphical dependences showed that at a pressure of $0.5 \mathrm{MPa}$, the decrease in the TCR significantly decreases, which is a consequence of the fact that the number of newly-contacted roughness ridges in relation to the number of initial contacts grows more slowly, and, therefore, contact [1]. As can be seen from the calculation results, when spraying is applied, the TCR value decreases by a factor of 2-3, which corresponds to the experimental data [10].

For a comparative analysis of the application of coatings for the regulation of TCR, the simulation results obtained by sputtering chromium, copper and lead are presented. (Figure $6)$.

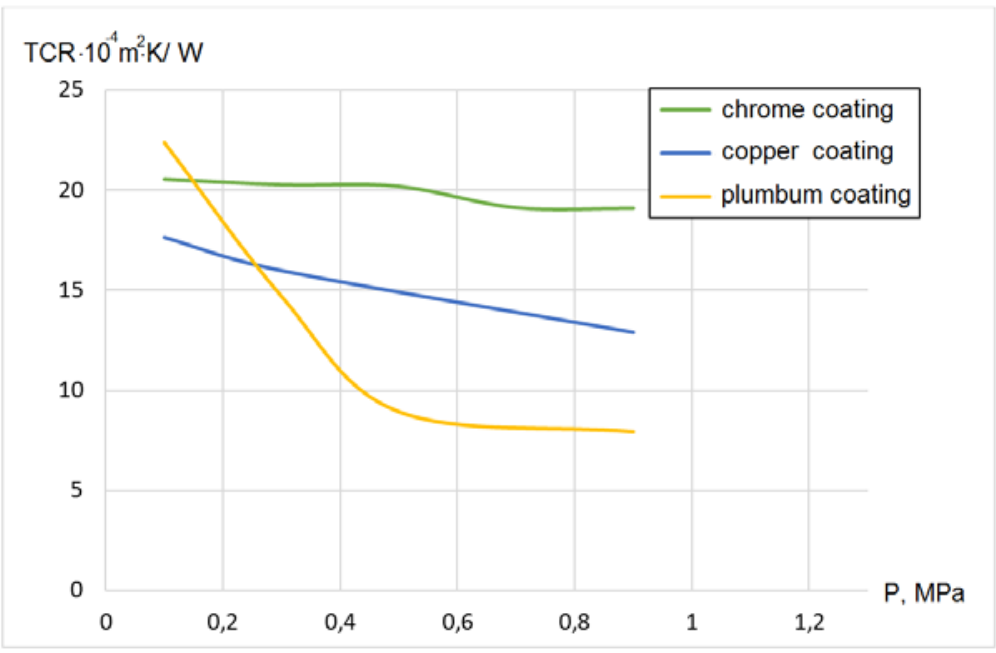

Fig. 6. Graph of the dependence of the TCR on the compression force, taking into account the deposition of chromium, copper and lead. 


\section{Conclusion}

The analysis showed that the use of a lead coating makes it possible to reduce the value of the contact thermal resistance by a factor of 2-3 in comparison with an uncoated contact. Also, from the results obtained, it can be seen that with compressive loads from $0.3 \mathrm{MPa}$ to $0.9 \mathrm{MPa}$, the value of TCR when using a leaded one of the surfaces is preferable, and allows you to reduce its value by 2 times. Thus, the results of the analyzes carried out, their comparison with experimental data, allows us to assert that this technique allows one to obtain reliable results when calculating the TCR and can be used for similar calculations to determine the heat-stressed state of a contact pair, taking into account the presence of coatings.

\section{References}

1. Yu P Shlykov,E A Ganin, S N Tsarevsky Contact thermal resistance, Energia (1977), pp 327

2. $\mathrm{S} \mathrm{Yu}$ Mesnyankin Methods for calculating and regulating contact thermal resistance // Sbornik nauchnih trudov «Teplovoe proektirovanie sistem» // MAI (1990), pp 78-86

3. A D Ezhov, L V Bykov,S Yu Mesnyankin, E A Bogachev, A S Razina Refinement and optimization of structural elements taking into account thermal deformations // Teplovie procesi v tehnike (2015). N 11.pp 510-516

4. N B Demkin, E V Ryzhov Surface quality and contact of machine components Mashinostroenie, Moscow (1981).

5. A.D. Ezhov, L.V. Bykov, S.Yu. Mesnyankin. Numerical Method for Determining the Real Contact Area of Contacting Bodies // Journal of Surface Investigation: X-ray, Synchrotron and Neutron Techniques. (September 2018), Volume 12, Issue 5, pp 914-917

6. L.V. Bykov, N.V. Artemchuk., A.D. Ezhov. Three-dimensional of modeling microgeometry of contact pairs in technical systems // IOP Conference Series: Materials Science and Engineering, Volume 709 (2020) 022057, issue 1, doi:10.1088/1757-899X/709/2/022057, 5 P.

7. A A Matalin,V S, Ristsova Surface cleanliness of parts to be coated, Maghiz, (1952)

8. V SMiller, An effective way to reduce the contactor thermal resistance, IFK, 1963

9. S Yu Mesnyankin,A G Vikulov, D G Vikulov A modern view on the problems of thermal contact of solids. // UFN. т.179, №9 (2009), pp 945-970.

10. V M Popov, Heat transfer in the contact zone of detachable and permanent connections, Energia, (1971), pp 216 